\title{
Lenvatinib May Drastically Change the Treatment Landscape of Hepatocellular Carcinoma
}

\author{
Masatoshi Kudo \\ Department of Gastroenterology and Hepatology, Kindai University Faculty of Medicine, \\ Osaka-Sayama, Japan
}

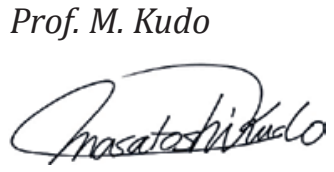

Editor Liver Cancer

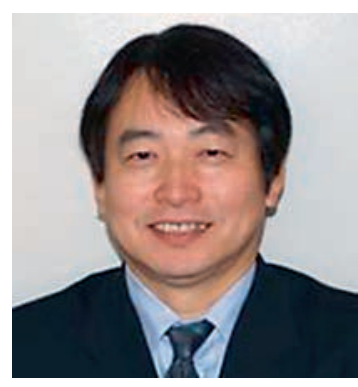

\section{Introduction}

Sorafenib, which was shown to improve survival in the SHARP [1] and Asia-Pacific [2] trials, has been the standard therapy for unresectable hepatocellular carcinoma (HCC) since 2007.

Since then, several first-line clinical trials have been conducted with the aim of developing molecular targeted agents showing better efficacy or safety than sorafenib [3] (Table 1). A superiority trial comparing sorafenib with sunitinib (SUN1170 trial) showed that sunitinib is not superior but rather significantly inferior to sorafenib regarding the primary endpoint of overall survival (OS) [4]. The BRISK-FL and LiGHT trials showed that brivanib and linifanib are not superior and, moreover, not noninferior, despite the fact that the trial designs allowed for assessment of noninferiority [5, 6]. A superiority trial of sorafenib plus erlotinib (SEARCH trial) [7], a superiority trial of sorafenib plus doxorubicin (CALGB808028 trial), and a trial investigating sorafenib plus hepatic arterial infusion chemotherapy (HAIC) (SILIUS trial) [8] all failed. The results of two superiority trials comparing sorafenib with radioembolization called SARAH (SorAfenib versus Radioembolization in Advanced Hepatocellular carcinoma) [9] and SIRveNIB (Study to Compare Selective Internal Radiation Therapy [SIRT] Versus Sorafenib in Locally Advanced Hepatocellular Carcinoma [HCC]) were also reported at EASL 2017 and ASCO 2017, although these trials failed as well [10]. These results highlight the diffi- 
Liver
Cancer

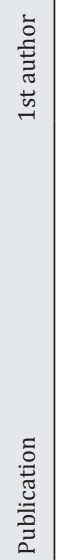

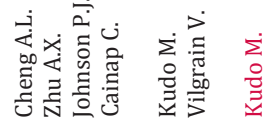

递文流㐫

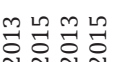

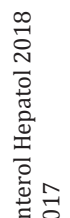

它它它它

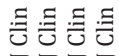

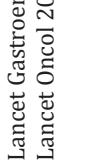

芯

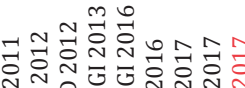

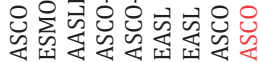

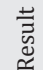

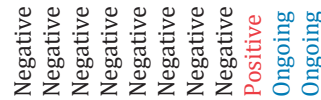

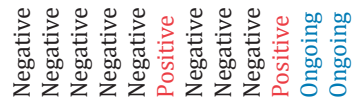

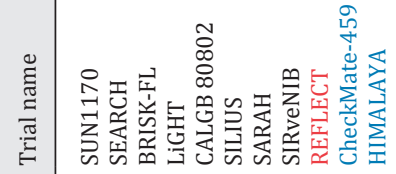

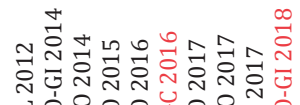

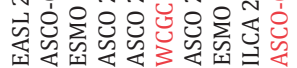

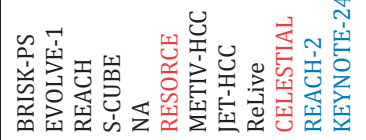

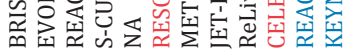

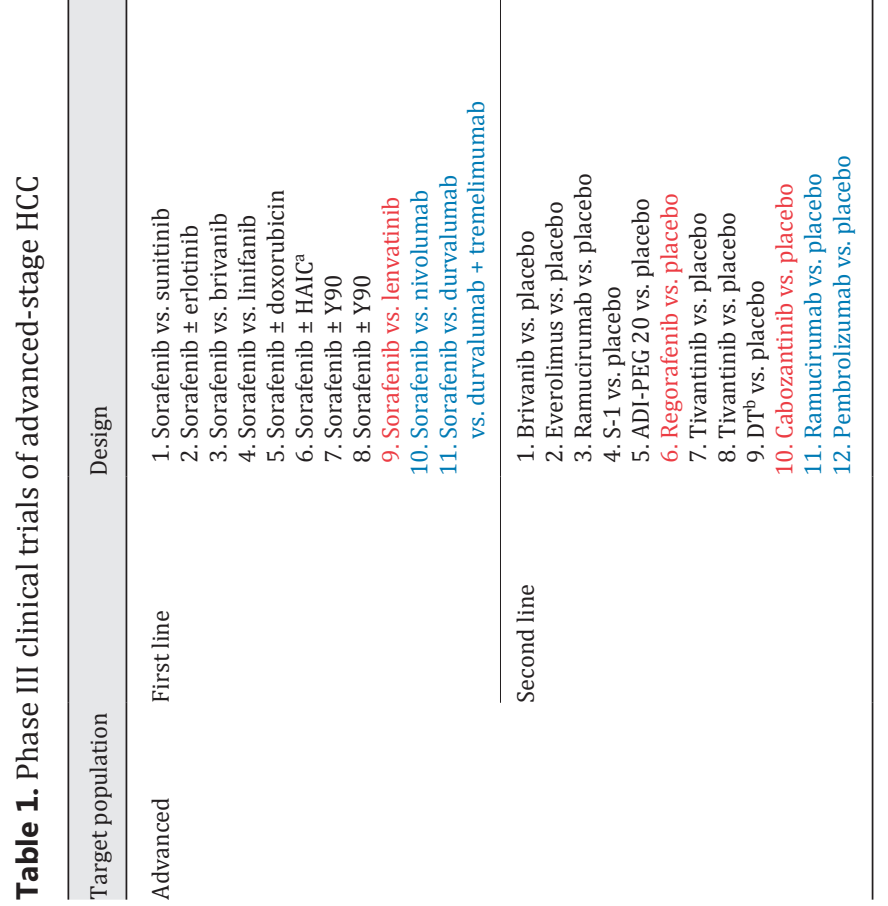

(C) 2018 S. Karger AG, Basel

www.karger.com/lic

Kudo: Lenvatinib May Drastically Change the Treatment Landscape of Hepatocellular Carcinoma
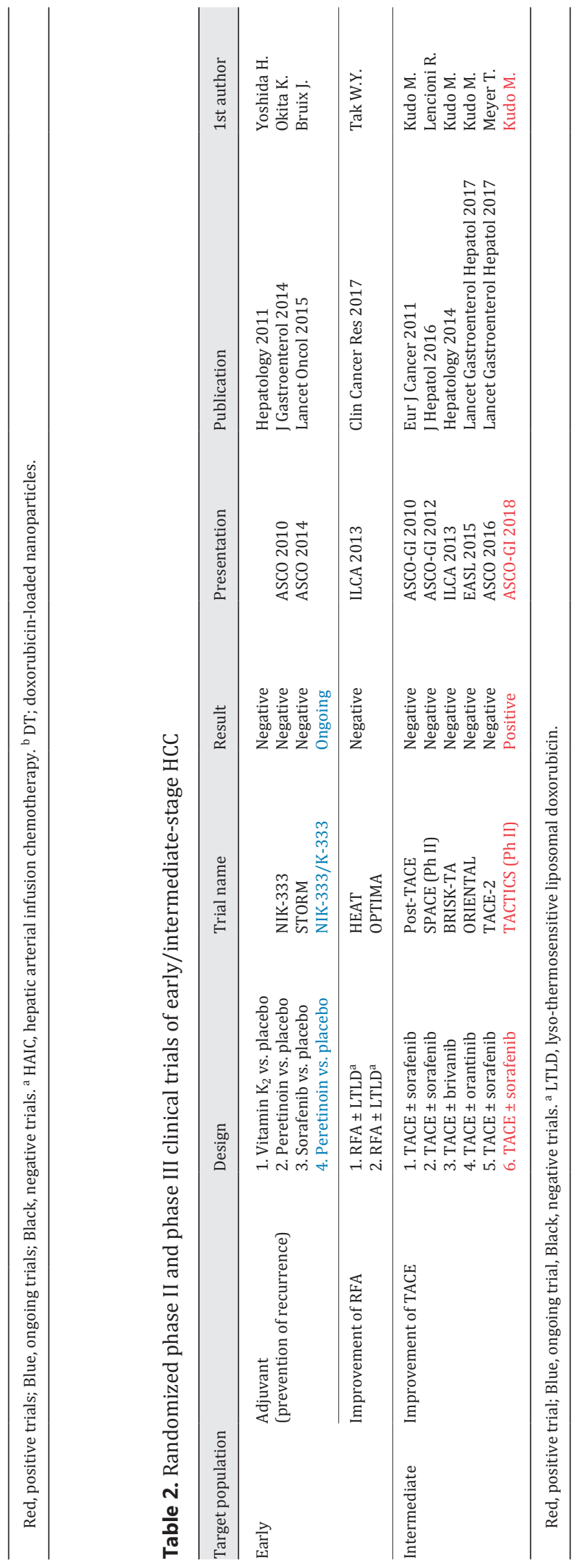


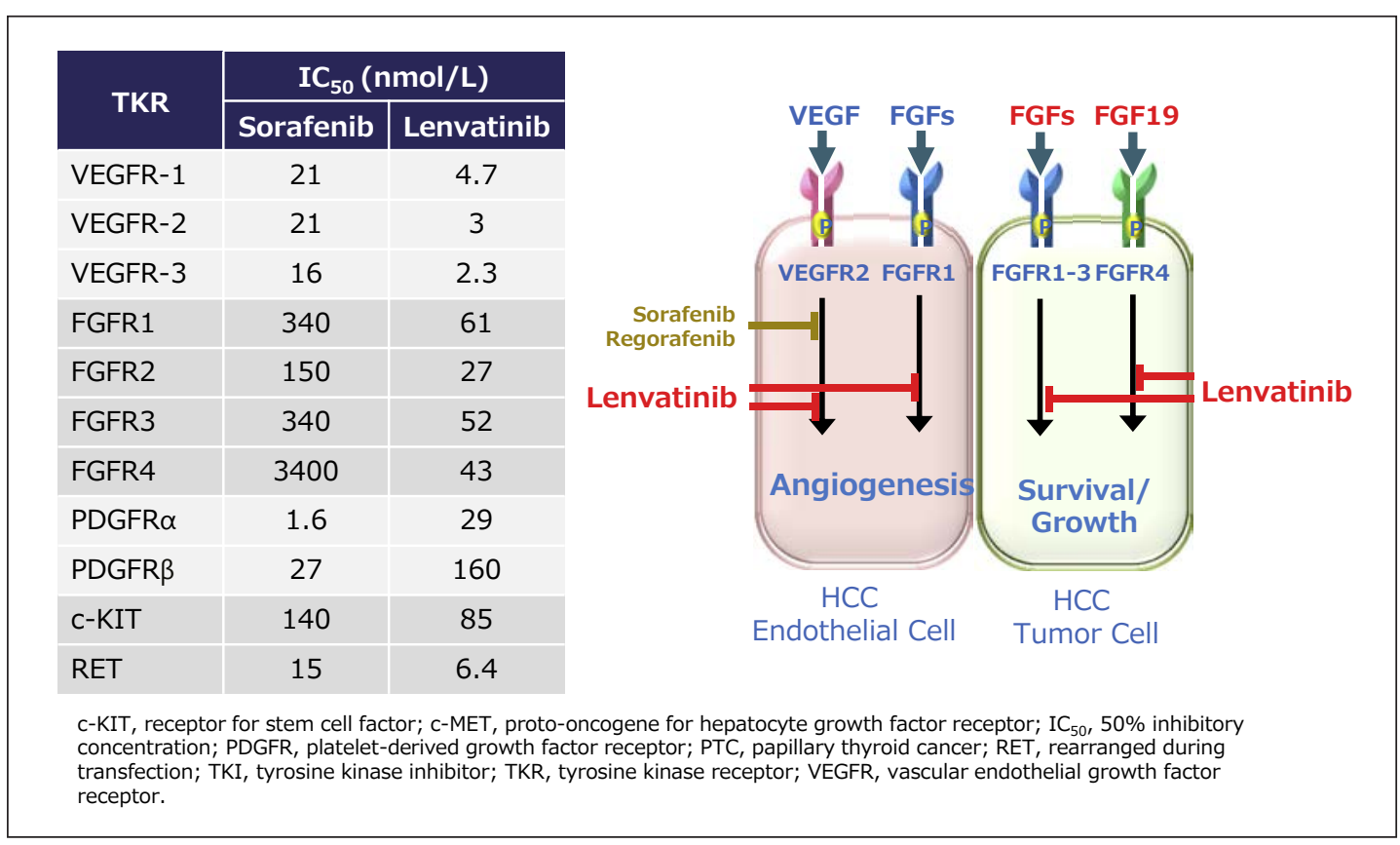

Fig. 1. Dual inhibition of VEGF and FGF pathways by lenvatinib (cited from Tohyama et al. [13]).

culties associated with conducting clinical trials of first-line HCC drugs using OS as the endpoint, and demonstrate the superiority of sorafenib for improving survival compared with other drugs.

Amid these failed trials, the results of a phase III trial of lenvatinib and sorafenib were presented at ASCO 2017. The trial met the primary endpoint of noninferiority, a shocking result that produced the greatest breakthrough in 10 years, suggesting a new option for firstline molecular targeted therapy [11]. Another recent development was the improvement in progression-free survival (PFS) achieved with sorafenib plus transcatheter arterial chemoembolization (TACE), as this approach was extremely challenging to develop (Table 2) [12].

\section{Development History of Lenvatinib}

Lenvatinib was discovered at Tsukuba Research Laboratory in Japan as a result of exploratory research on angiogenesis inhibitors. It primarily inhibits vascular endothelial growth factor (VEGF) receptors (VEGFR1-3), fibroblast growth factor (FGF) receptors (FGFR1-4), KIT, and RET [13]. Lenvatinib simultaneously suppresses the activity of factors involved in tumor angiogenesis while also suppressing proliferation signals from VEGFR and FGFR, which are strongly expressed in cancer cells. Because of these properties, lenvatinib is an extremely effective inhibitor of angiogenesis (Fig. 1) [14]. Inhibition of FGFR4 in particular is considered a critical and important factor in the antitumor effects of lenvatinib [15-19].

The recommended dose is $24 \mathrm{mg} /$ day based on the results of phase I trials in solid cancers and subsequent trials in other cancers. However, a recommended dose had to be established specifically for patients with HCC, because lenvatinib is primarily metabolized by cytochrome P450 3A in the liver, and could potentially have a different adverse event (AE) profile in patients with HCC associated with liver cirrhosis than in patients with other solid cancers. A phase I trial in patients with Child-Pugh A and B HCC was conducted for that purpose. Based 
Kudo: Lenvatinib May Drastically Change the Treatment Landscape of Hepatocellular Carcinoma

Table 3. REFLECT: investigator assessment according to mRECIST

\begin{tabular}{lllll}
\hline & $\begin{array}{l}\text { Lenvatinib } \\
(n=478)\end{array}$ & $\begin{array}{l}\text { Sorafenib } \\
(n=476)\end{array}$ & HR/OR & $p$ value \\
\hline OS, months & $13.6(12.1-14.9)$ & $12.3(10.4-13.9)$ & HR $0.92(0.79-1.06)$ & - \\
PFS, months & $7.4(6.9-8.8)$ & $3.7(3.6-4.6)$ & HR $0.66(0.57-0.77)$ & $<0.0001$ \\
TTP, months & $8.9(7.4-9.2)$ & $3.7(3.6-5.4)$ & HR $0.63(0.53-0.73)$ & $<0.0001$ \\
ORR, \% & $24.1(20.2-27.9)$ & $9.2(6.6-11.8)$ & OR 3.13 $(2.15-4.56)$ & $<0.0001$ \\
\hline
\end{tabular}

Values in parentheses are 95\% CI. OS, overall survival; PFS, progression-freesurvival; TTP, time to progression; ORR, objective response rate; HR, hazard ratio; OR, odds ratio. Cited and modified from Kudo et al. [11].

on the results, the recommended dose was set at $12 \mathrm{mg} /$ day for Child-Pugh A patients and 8 $\mathrm{mg} /$ day for Child-Pugh B patients [20].

A phase II trial in patients with HCC conducted in Japan and South Korea confirmed the potent antitumor effect of lenvatinib and the feasibility of managing AEs in patients with HCC [21]. A later detailed analysis of the pharmacokinetics of lenvatinib in patients with HCC determined that the optimal dose was $8 \mathrm{mg}$ /day for patients weighing less than $60 \mathrm{~kg}$ and 12 $\mathrm{mg} /$ day for patients weighing $60 \mathrm{~kg}$ or more. These findings sparked the planning of a phase III trial comparing lenvatinib with sorafenib (REFLECT trial).

\section{Overview of the REFLECT Trial Results}

The REFLECT trial was a global, randomized, open-label, phase III noninferiority trial. The trial enrolled patients with unresectable HCC with no history of systemic chemotherapy, and they were randomized 1:1 to lenvatinib and sorafenib arms. Patients were stratified by region (Asia or non-Asia), macroscopic portal vein involvement and/or extrahepatic spread, ECOG performance status ( 0 or 1 ), and body weight ( $<60 \mathrm{~kg}$ or $\geq 60 \mathrm{~kg}$ ). Treatment was continued until disease progression or onset of an intolerable AE. Noninferiority of OS was set as the primary endpoint, and the noninferiority margin was set at 1.08. Time to progression (TTP), PFS, objective response rate (ORR), and safety were evaluated as secondary endpoints.

Of the 954 patients enrolled, 478 were assigned to the lenvatinib arm and 476 to the sorafenib arm. In the lenvatinib arm, $67 \%$ of enrolled patients were from the Asia-Pacific region and 33\% were from Western countries. Body weight was $<60 \mathrm{~kg}$ in $32 \%$ and $\geq 60 \mathrm{~kg}$ in $68 \%$ of patients. Macroscopic vein involvement and/or extrahepatic spread was detected in $69 \%$ of patients, and $78 \%$ were Barcelona clinic liver cancer stage C. The proportion of patients with HCC caused by hepatitis $\mathrm{C}$ was favorably imbalanced toward sorafenib (26 vs. $19 \%$ in the lenvatinib arm) [11]. Conversely, the proportion of patients with HCC caused by hepatitis B was $53 \%$ in the lenvatinib arm and $48 \%$ in the sorafenib arm. The proportion of patients with an $\alpha$-fetoprotein (AFP) level of $\geq 200 \mathrm{ng} / \mathrm{mL}$ was also favorably imbalanced toward sorafenib ( 39 vs. $46 \%$ in the lenvatinib arm).

The primary endpoint of OS was 13.6 months in the lenvatinib arm and 12.3 months in the sorafenib arm. The upper limit of the $95 \%$ confidence interval (CI) of the hazard ratio (HR), which was $0.92(0.79-1.06)$, was below the predetermined noninferiority margin of 1.08, which demonstrated the statistically significant noninferiority of lenvatinib with respect to OS [11]. PFS, TTP, and ORR (lenvatinib arm/sorafenib arm) per investigator assessment using the modified RECIST criteria (mRECIST) were 7.4/3.7 months, 8.9/3.7 months, and $24.1 / 9.2 \%$, respectively. These results demonstrate that lenvatinib had a statistically signifi- 
Kudo: Lenvatinib May Drastically Change the Treatment Landscape of Hepatocellular Carcinoma

Table 4. REFLECT: masked independent imaging review according to mRECIST

\begin{tabular}{lcccc}
\hline & $\begin{array}{l}\text { Lenvatinib } \\
(n=478)\end{array}$ & $\begin{array}{l}\text { Sorafenib } \\
(n=476)\end{array}$ & HR/OR & $p$ value \\
\hline PFS, months & $7.3(5.6-7.5)$ & $3.7(3.6-3.7)$ & HR 0.64 (0.55-0.75) & $<0.0001$ \\
TTP, months & $7.4(7.2-9.1)$ & $3.7(3.6-3.9)$ & HR 0.60 (0.51-0.71) & $<0.0001$ \\
ORR, \% & $40.6(36.2-45.0)$ & $12.4(9.4-15.4)$ & OR 5.01(3.59-7.01) & $<0.0001$ \\
\hline
\end{tabular}

Values in parentheses are 95\% CI. PFS, progression-free survival; TTP, time to progression; ORR, objective response rate; HR, hazard ratio; OR, odds ratio. Cited and modified from Kudo et al. [11].

Table 5. REFLECT: masked independent imaging review according to RECIST1.1

\begin{tabular}{lcclc}
\hline & $\begin{array}{l}\text { Lenvatinib } \\
(n=478)\end{array}$ & $\begin{array}{l}\text { Sorafenib } \\
(n=476)\end{array}$ & HR/OR & $p$ value \\
\hline PFS, months & $7.3(5.6-7.5)$ & $3.6(3.6-3.9)$ & HR 0.65 (0.56-0.77) & $<0.0001$ \\
TTP, months & $7.4(7.3-9.1)$ & $3.7(3.6-5.4)$ & HR 0.61 $(0.51-0.72)$ & $<0.0001$ \\
ORR, \% & $18.8(15.3-22.3)$ & $6.5(4.3-8.7)$ & OR 3.34 (2.17-5.14) & $<0.0001$ \\
\hline
\end{tabular}

Values in parentheses are 95\% CI. PFS, progression-free survival; TTP, time to progression; ORR, objective response rate; HR, hazard ratio; OR, odds ratio. Cited and modified from Kudo et al. [11].

cantly better antitumor effect than sorafenib (Table 3) [11]. Another surprising finding was that tumor shrinkage according to the masked independent imaging review using mRECIST was considerably greater in the lenvatinib arm than in the sorafenib arm (ORR: 40.6 vs. $12.4 \%$ ) (Table 4) [11]. This favorable antitumor effect indicated by the PFS, TTP, and ORR rates was reproduced exactly in a masked independent imaging review using RECIST 1.1 (Table 5) [11].

Since patients were not stratified by AFP in this trial, the lenvatinib arm had a higher proportion of patients with AFP of $\geq 200 \mathrm{ng} / \mathrm{mL}$. When this AFP imbalance was corrected by analysis of covariance in the OS analysis, lenvatinib demonstrated a statistically significant superior effect over sorafenib with respect to OS (HR $=0.856,95 \% \mathrm{CI}=0.736-0.995$, nominal $p=0.0342$ ) (Fig. 2) [11]. This result indicates that the trial may have demonstrated superiority if patients had been stratified by AFP.

In the OS subanalysis, lenvatinib was superior to sorafenib for improving OS in almost all groups. One particularly noteworthy finding was that lenvatinib was more effective than sorafenib for improving OS even in patients weighing $<60 \mathrm{~kg}$ who received a dose of only 8 $\mathrm{mg}$, and the HR was even better than that in patients weighing $\geq 60 \mathrm{~kg}$ who received $12 \mathrm{mg}$ (< $60 \mathrm{~kg}: \mathrm{HR}=0.85 \mathrm{vs} . \geq 60 \mathrm{~kg}: \mathrm{HR}=0.95$ ). This indicated that weight-based dosing is successful. Lenvatinib also yielded a good improvement in OS in patients with high AFP, a poor prognostic factor, as indicated by the HR of $0.78(95 \% \mathrm{CI}=0.63-0.98)$ (Fig. 2). The only subgroup in which the numerical values indicated that sorafenib yielded better OS was that of patients enrolled in Western countries. This can be attributed to the fact that patients in the sorafenib arm in those countries frequently received post-study systemic anticancer treatment (38.9 vs. $26.1 \%$ in the lenvatinib arm), and patients in the sorafenib arm more frequently underwent anticancer procedures such as TACE (11.5 vs. $7.0 \%$ in the lenvatinib arm) (Table 6) [11]. In the Asia-Pacific region, the percentage of patients who received post-study therapy was well balanced; however, in the Western region, $45.2 \%$ of patients in the sorafenib arm received 


\section{Liver Cancer}

\begin{tabular}{l|l}
\hline \multicolumn{2}{l}{ Liver Cancer 2018;7:1-19 } \\
\hline DOI: 10.1159/000487148 & $\begin{array}{l}\text { C 2018 S. Karger AG, Basel } \\
\text { www.karger.com/lic }\end{array}$ \\
\hline
\end{tabular}

Kudo: Lenvatinib May Drastically Change the Treatment Landscape of Hepatocellular Carcinoma

Table 6. Post-study anticancer therapy during survival follow-up

\begin{tabular}{|c|c|c|c|c|c|c|}
\hline & \multicolumn{3}{|l|}{ Lenvatinib } & \multicolumn{3}{|l|}{ Sorafenib } \\
\hline & $\begin{array}{l}\text { Asia-Pacific } \\
\text { subgroup } \\
(n=321)\end{array}$ & $\begin{array}{l}\text { Western } \\
\text { subgroup } \\
(n=157)\end{array}$ & $\begin{array}{l}\text { total } \\
(n=478)\end{array}$ & $\begin{array}{l}\text { Asia-Pacific } \\
\text { subgroup } \\
(n=319)\end{array}$ & $\begin{array}{l}\text { Western } \\
\text { subgroup } \\
(n=157)\end{array}$ & $\begin{array}{l}\text { total } \\
(n=476)\end{array}$ \\
\hline $\begin{array}{l}\text { Received any anticancer therapy } \\
\text { during survival follow-up, } n(\%)\end{array}$ & $162(50.5)$ & $44(28.0)$ & $206(43.1)$ & $172(53.9)$ & $71(45.2)$ & 243 (51.1) \\
\hline $\begin{array}{l}\text { Received any anticancer medication } \\
\text { (not given for any procedure) during } \\
\text { survival follow-up, } n(\%)\end{array}$ & $115(35.8)$ & $41(26.1)$ & $156(32.6)$ & $123(38.6)$ & 61 (38.9) & 184 (38.7) \\
\hline $\begin{array}{l}\text { Underwent any anticancer procedure } \\
\text { during survival follow-up, } n(\%)\end{array}$ & $111(34.6)$ & $11(7.0)$ & $122(25.5)$ & $112(35.1)$ & 18 (11.5) & $130(27.3)$ \\
\hline
\end{tabular}

Anticancer therapy includes anticancer medication and anticancer procedure. Cited from Kudo et al. [11].

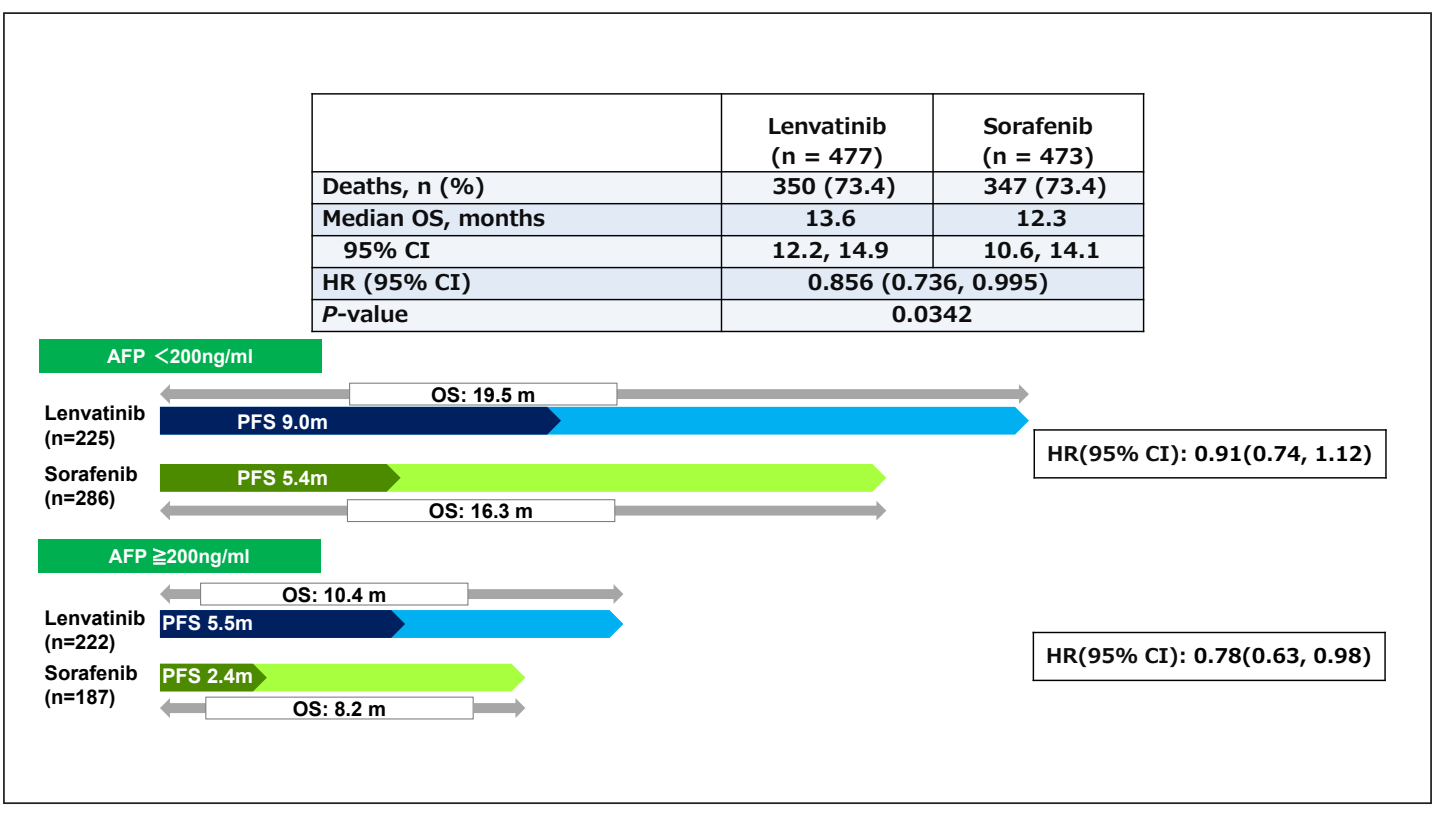

Fig. 2. Overall survival adjusted by baseline AFP $(<200 \mathrm{ng} / \mathrm{mL}$ and $\geq 200 \mathrm{ng} / \mathrm{mL})$. AFP, $\alpha$-fetoprotein; HR, hazard ratio.

post-study treatmentversus $28.0 \%$ in the lenvatinib arm. An imbalance between the treatment arms was observed in the proportion of patients who received post-anticancer therapy during the survival follow-up, which was higher in the sorafenib than in the lenvatinib arm: $51.1 \%$ $(243 / 476)$ versus $43.1 \%$ (206/478), respectively. In post-study treatment, new agents were used in $17.0 \%$ of patients in the sorafenib arm compared with $5.9 \%$ in the lenvatinib arm. In the lenvatinib arm, $25.3 \%$ of patients received sorafenib after progression, and $11.8 \%$ of patients in the sorafenib arm were rechallenged with sorafenib (Table 7) [22]. 


\section{Liver Cancer}

\begin{tabular}{l|l}
\hline Liver Cancer 2018;7:1-19 \\
\hline DOI: 10.1159/000487148 & $\begin{array}{l}\text { (c) 2018 S. Karger AG, Basel } \\
\text { www.karger.com/lic }\end{array}$ \\
\hline
\end{tabular}

Kudo: Lenvatinib May Drastically Change the Treatment Landscape of Hepatocellular Carcinoma

Table 7. Subsequent anticancer therapy during survival follow-up

\begin{tabular}{lcc}
\hline & $\begin{array}{c}\text { Lenvatinib } \\
(n=478), n(\%)\end{array}$ & $\begin{array}{l}\text { Sorafenib } \\
(n=476), n(\%)\end{array}$ \\
\hline Subjects with any anticancer medication $^{\mathrm{a}}$ & $156(32.6)$ & $184(38.7)$ \\
$\quad$ Post-study treatment with new agents & $28(5.9)$ & $81(17.0)$ \\
$\quad$ Investigational drugs & $20(4.2)$ & $73(15.3)$ \\
$\quad$ Checkpoint inhibitors & $9(1.9)$ & $9(1.9)$ \\
Cytotoxic chemotherapy & $44(9.2)$ & $56(16.2)$ \\
Sorafenib & $121(25.3)$ & $31(6.5)$ \\
Other & $25(5.2)$ &
\end{tabular}

${ }^{a}$ Anticancer medication: not given for any procedure. ${ }^{b}$ Investigational drugs including drugs coded as investigational drugs, tivantinib, regorafenib, cabozantinib, and the other VEGF inhibitors.

Treatment duration was 5.7 months in the lenvatinib arm and 3.7 months in the sorafenib arm, indicating that treatment with lenvatinib was better tolerated. Dose intensity of the planned starting dose was also slightly better in the lenvatinib arm than in the sorafenib arm (88 vs. $83 \%$ ).

The above results demonstrate the statistically significant noninferiority of lenvatinib over sorafenib with respect to OS, and statistically and clinically meaningful improvements were also observed in the secondary endpoints (PFS, TTP, and ORR). These findings indicate that lenvatinib is an effective first-line drug for unresectable HCC.

\section{Factors Contributing to the Success of the REFLECT Trial}

Several critical factors contributed to the first successful demonstration of noninferiority of a first-line drug in 10 years. The REFLECT trial was the first noninferiority trial of a molecular targeted agent with dose selection by body weight (12 vs. $8 \mathrm{mg}$ ). In the GIDEON observational study, only $45.5 \%$ of Japanese patients started sorafenib at $800 \mathrm{mg}$, and there was no clear evidence to support reducing doses based on patients' body weight [23]. In the lenvatinib arm, the same level of efficacy was obtained across weight groups $(<60 \mathrm{~kg}$ and $\geq 60$ $\mathrm{kg}$ ), and toxicity was within an acceptable range. The incidence of hand-foot skin reaction and diarrhea was lower, enabling longer treatment duration in the lenvatinib than in the sorafenib arm. The antitumor effect was surprisingly better (ORR: 40.6\%), and no other molecular targeted drug has yielded such good response rates (Fig. 3, 4) [24-27]. PFS and TTP were also better for lenvatinib than for sorafenib, supporting that its antitumor effect is more potent than that of sorafenib. Another factor contributing to the success of the trial was that patients could receive an additional 2 months of treatment with lenvatinib because of its acceptable $\mathrm{AE}$ profile and slightly greater tolerability than sorafenib in some respects.

The REFLECT trial did not demonstrate superiority over sorafenib likely because of the unfavorably high proportion of high-AFP patients in the lenvatinib arm, which was due to the lack of stratification by AFP and macroscopicvein involvement, as well as the higher proportion of patients with hepatitis C (a favorable prognostic factor for sorafenib) in the sorafenib arm [28]. Another possible reason was that both arms consisted of patients with favorable prognosis who were good candidates for post-study treatment because of the exclusion of patients with tumor thrombus at the main portal vein (VP4) and $\geq 50 \%$ tumor occupancy in the liver $[29,30]$. The longer post-progression survival associated with post-study treatment in both arms may have diluted the OS benefit, as observed in previous failed trials [31-33]. In fact, 
Kudo: Lenvatinib May Drastically Change the Treatment Landscape of Hepatocellular

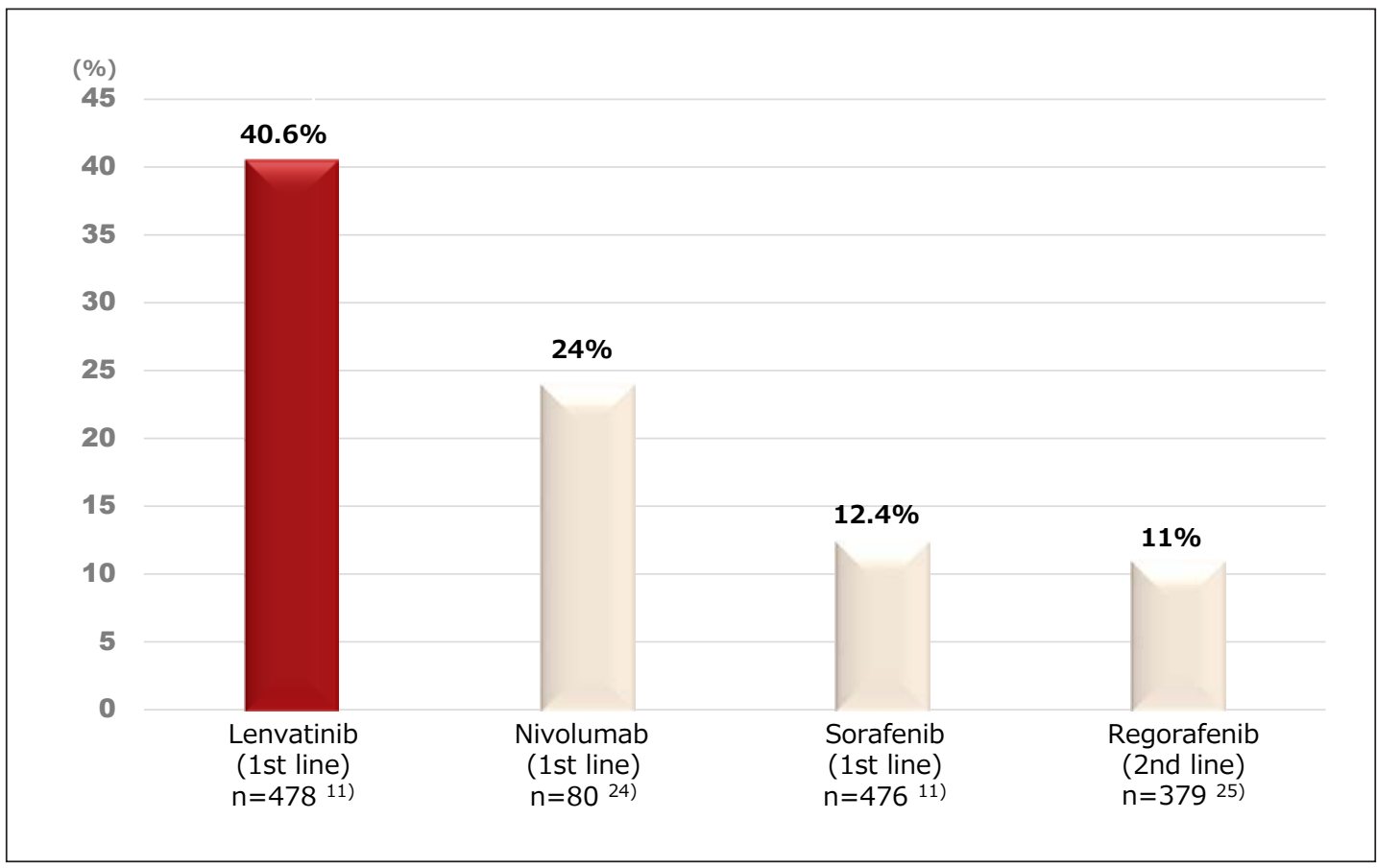

Fig. 3. Objective response rate by mRECIST in systemic therapy [11, 24, 25].

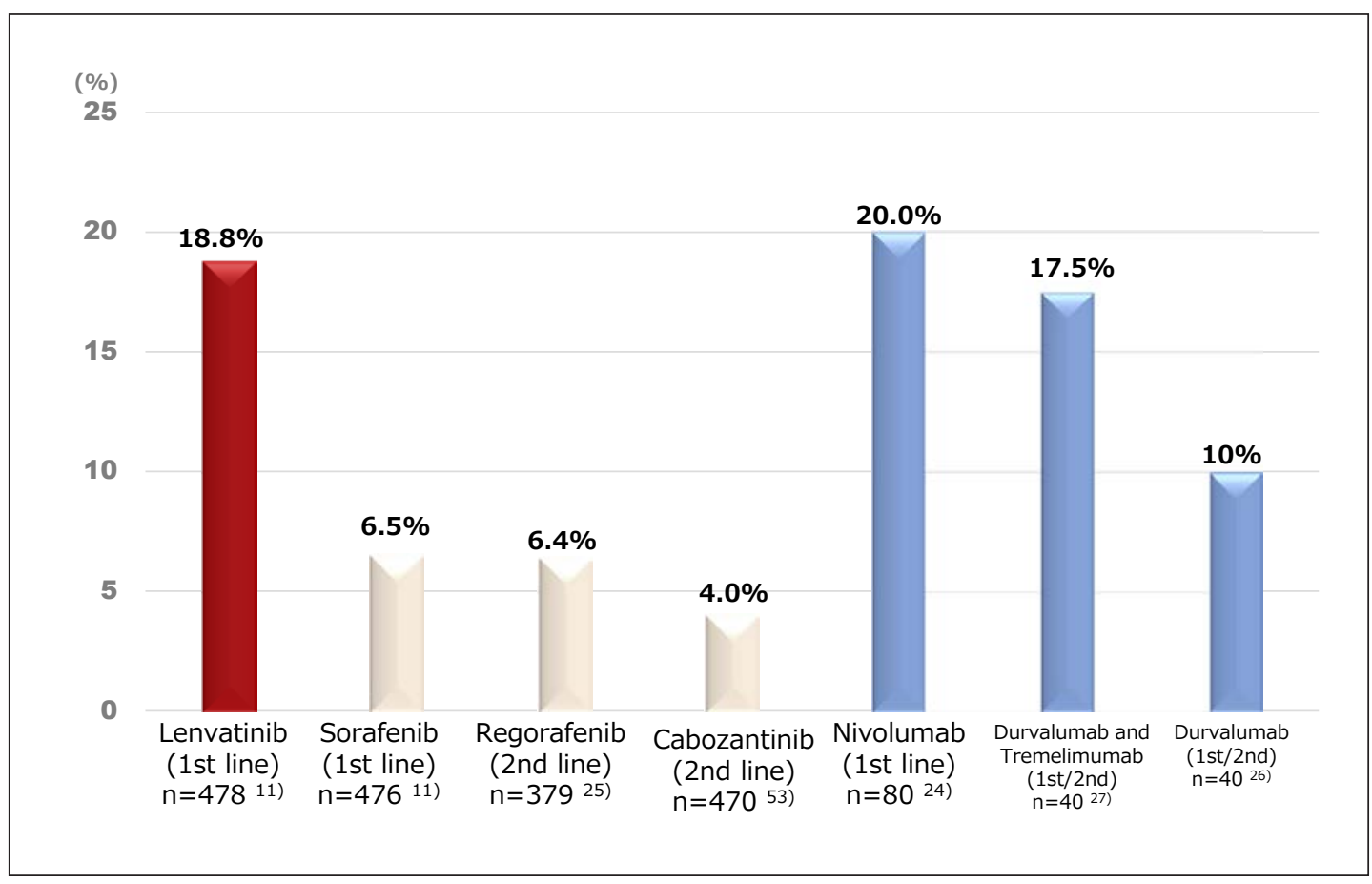

Fig. 4. Objective response rate by RECIST1.1 in systemic therapy [11, 24-27, 53]. 


\section{Liver
Cancer}

\begin{tabular}{l|l}
\hline Liver Cancer 2018;7:1-19 \\
\hline DOI: 10.1159/000487148 & $\begin{array}{l}\text { (c) 2018 S. Karger AG, Basel } \\
\text { www.karger.com/lic }\end{array}$ \\
\hline
\end{tabular}

Kudo: Lenvatinib May Drastically Change the Treatment Landscape of Hepatocellular Carcinoma

Table 8. Stratification factors in phase III clinical trials in first-line agents for HCC

\begin{tabular}{|c|c|c|c|c|c|c|}
\hline $\begin{array}{l}\text { Study arm vs. } \\
\text { sorafenib arm }\end{array}$ & $\begin{array}{l}\text { SUN1170 } \\
\text { (sunitinib) }\end{array}$ & $\begin{array}{l}\text { BRISK-FL } \\
\text { (brivanib) }\end{array}$ & $\begin{array}{l}\text { LiGHT } \\
\text { (linifanib) }\end{array}$ & $\begin{array}{l}\text { SEARCH } \\
\text { (+ erlotinib) }\end{array}$ & $\begin{array}{l}\text { CheckMate- } 459 \\
\text { (nivolumab) }\end{array}$ & $\begin{array}{l}\text { REFLECT } \\
\text { (lenvatinib) }\end{array}$ \\
\hline $\begin{array}{l}\text { Stratification } \\
\text { factor }\end{array}$ & $\begin{array}{l}\text { Region } \\
\text { Vascular invasion } \\
\text { and/or extrahepatic } \\
\text { spread } \\
\text { Prior TACE }\end{array}$ & $\begin{array}{l}\text { Region } \\
\text { ECOG-PS score } \\
\text { Extrahepatic } \\
\text { spread and/or } \\
\text { vascular invasion }\end{array}$ & $\begin{array}{l}\text { Region } \\
\text { ECOG-PS score } \\
\text { Vascular invasion } \\
\text { and/or extrahepatic } \\
\text { spread } \\
\text { Hepatitis B virus } \\
\text { infection }\end{array}$ & $\begin{array}{l}\text { Region } \\
\text { ECOG-PS score } \\
\text { Vascular invasion } \\
\text { and/or extrahepatic } \\
\text { spread } \\
\text { Smoking status }\end{array}$ & $\begin{array}{l}\text { Region } \\
\text { Vascular invasion } \\
\text { and/or extrahepatic } \\
\text { spread } \\
\text { Etiology }\end{array}$ & $\begin{array}{l}\text { Region } \\
\text { ECOG-PS score } \\
\text { Vascular invasion } \\
\text { and/or extrahepatic } \\
\text { spread } \\
\text { Body weight }\end{array}$ \\
\hline
\end{tabular}

Cited and modified from previously published studies $[4-7,11,56]$.

patients in both the lenvatinib and sorafenib arms of the REFLECT trial received a significant amount of post-study treatment (Tables 6,7 ), which resulted in extremely long OS in the sorafenib arm (12.3 months), the longest ever observed in clinical trials of first-line agents (SHARP: 10.7 months, Asia-Pacific: 6.5 months, SUN1170: 10.2 months, Brisk-FL: 9.9 months, LiGHT: 9.8 months) [1, 2, 4-6].

The imbalance in AFP was a critical issue. This was an accidental imbalance resulting from the lack of inclusion of AFP as a stratification factor. However, AFP was not commonly used as a stratification factor when the REFLECT trial was started, and it was not included in any past or current first-line trials [4-7, 11] (Table 8). In their review, Llovet et al. [34] do not recommend using AFP as a stratification factor in first-line trials. Nevertheless, as noted above, lenvatinib demonstrated statistically significant superiority over sorafenib with respect to OS when the AFP imbalance was corrected by analysis of covariance, indicating that AFP should be used as a stratification factor in future first-line trials.

\section{AE Profile}

Certain AEs were slightly more frequent in the lenvatinib arm than in the sorafenib arm, including hypertension, proteinuria, dysphonia, and hypothyroidism. Hand-foot skin reaction, diarrhea, and hair loss were slightly more frequent in the sorafenib arm than in the lenvatinib arm. The low incidence of hand-foot skin reaction, diarrhea, and other events that directly impact compliance is one reason that patients continued lenvatinib for a longer period than sorafenib. However, treatment-emergent AEs (TEAEs) of all grades were more frequent in the lenvatinib arm; the incidence of TEAEs of grade 3 or higher in particular was higher in the lenvatinib arm than in the sorafenib arm (57 vs. 49\%), and the incidence of serious TEAEs was also slightly higher in the lenvatinib arm than in the sorafenib arm (18 vs. 10\%) [11]. However, this can be attributed to the longer duration of treatment with lenvatinib $(+2$ months). The incidence of AEs of all grades, grade 3 or higher, as well as SAEs was either comparable between the two arms or lower in the lenvatinib arm after correction by actual treatment duration (Table 9) [35].

\section{Significance of Body Weight-Based Dosing}

In the phase II trial, a uniform daily dose of $12 \mathrm{mg}$ irrespective of body weight and surface area led to dose reduction in a large proportion of patients: dose adjustment occurred in 34 of 46 patients (74\%) because of treatment-related AEs, and withdrawal occurred in 10 patients $(22 \%)$ because of toxicity. Close examination of the patients' background suggested 
Kudo: Lenvatinib May Drastically Change the Treatment Landscape of Hepatocellular Carcinoma

Table 9. Treatment-emergent adverse events (TEAEs) adjusted by treatment duration

\begin{tabular}{lcc}
\hline & $\begin{array}{l}\text { Lenvatinib } \\
(n=476), \\
\text { AE rate }\end{array}$ & $\begin{array}{l}\text { Sorafenib } \\
(n=475), \\
\text { AE rate }\end{array}$ \\
\hline TEAEs & & \\
TEAE episodes & $18.89 \%$ & $19.73 \%$ \\
$\quad$ Related TEAE episodes & $10.94 \%$ & $11.98 \%$ \\
TEAE episodes of grade $\geq 3$ & $3.16 \%$ & $3.33 \%$ \\
$\quad$ Related TEAE episodes of grade $\geq 3$ & $1.59 \%$ & $1.80 \%$ \\
Serious TEAE episodes & $1.26 \%$ & $0.97 \%$ \\
$\quad$ Serious related TEAE episodes & $0.41 \%$ & $0.28 \%$ \\
Related episodes of TEAE leading to study drug: & & $0.97 \%$ \\
$\quad$ Dose reduction & $0.84 \%$ & $1.77 \%$ \\
$\quad$ Reductions or interruption & $1.59 \%$ & $0.18 \%$ \\
$\quad$ Withdrawal & $0.15 \%$ & \\
\hline
\end{tabular}

Lenvatinib, total duration 324.2 years; sorafenib, total duration 239.1 years.

that body weight and serum lenvatinib levels were associated with dose reduction or early treatment withdrawal. More precisely, patients who had dose reduction or early withdrawal within 30 days of lenvatinib treatment were significantly lighter (median weight, 54.1 vs. 67.6 $\mathrm{kg}$ ) and had a significantly higher minimum plasma concentration of lenvatinib (trough concentration [C1D15C $\mathrm{C}_{\text {trough }}$ ], $62.4 \mathrm{vs.} 33.9 \mathrm{ng} / \mathrm{mL}$ ) [36, 37].

\section{Relationship between Body Weight and Plasma Level of Lenvatinib in HCC Patients}

Following the phase I and II trials, population pharmacokinetics were analyzed in 65 HCC patients enrolled in those trials, and in 155 patients with solid cancer and 232 healthy individuals enrolled in other clinical trials [36]. A relationship was observed between body weight and plasma lenvatinib level (represented by the area under the blood concentration time curve [AUC]), indicating that exposure to lenvatinib increased as body weight decreased [36, 37]. This trend was more prominent in HCC patients than in patients with other types of solid cancers, suggesting that the relationship has an especially strong impact in HCC patients.

\section{Relationship between Pharmacokinetics of Lenvatinib and Dose Reduction or Withdrawal} in HCC Patients

Forty-five patients who participated in trials for HCC treatment were divided into a low AUC group $(<2,051.1 \mathrm{ng} \bullet \mathrm{h} / \mathrm{mL})$, an intermediate AUC group $(>2,051.1$ to $\leq 2,747.1 \mathrm{ng} \bullet \mathrm{h} / \mathrm{mL})$, and a high AUC group ( $>2,747.1 \mathrm{ng} \bullet \mathrm{h} / \mathrm{mL}$ ) to examine the relationship between AUC and time to dose reduction or withdrawal of lenvatinib. Kaplan-Meier plots showed a reduction in the time to dose reduction or withdrawal with increasing AUC [36, 37]. A similar relationship was observed between body weight and time to dose reduction or withdrawal; time to dose reduction or withdrawal became shorter as body weight decreased, demonstrating that dose reduction or withdrawal may be required earlier in lighter patients than in heavier patients $[36,37]$.

Optimal Cutoff Values for Body Weight and AUC in HCC Patients Treated with Lenvatinib

Strong correlations between lenvatinib withdrawal, blood concentration (AUC), and body weight indicated that dose adjustment by body weight and AUC may improve the safety of lenvatinib for the treatment of patients with HCC. The sensitivity and specificity of different 
body weight cutoff values for predicting the early occurrence (within 30 days after the start of therapy) of dose reduction and withdrawal were calculated to draw receiver operating characteristic (ROC) curves [36, 37]. The optimal body weight cutoff (the point at which the distance between the top left corner of the graph and the ROC is smallest) that most effectively distinguished the high-risk group for early withdrawal or dose reduction of lenvatinib was $57.8 \mathrm{~kg}$, showing a sensitivity of 0.77 and specificity of 0.67 (false-positive rate, 0.33 ). Similarly, the optimal AUC cutoff was $2,430 \mathrm{ng} \cdot \mathrm{h} / \mathrm{mL}$, with a sensitivity of 0.71 and specificity of 0.71 (false-positive rate, 0.29 ) [36, 37].

\section{Significance of Maintaining the AUC within a Certain Range and Lenvatinib Dose} Adjustment in HCC

Regarding the prediction of early withdrawal or dose reduction of lenvatinib, the AUC was more effective than other factors such as sex, body weight, age, liver function, platelet count, ECOG performance status, Child-Pugh class, hepatitis viral status, portal vein tumor thrombus, prior chemotherapy, prior antihypertensive therapy, and prior surgery. An AUC probability curve $[36,37]$ can predict early withdrawal or dose reduction of lenvatinib. Consequently, the AUC needs to be maintained below a certain level to reduce the occurrence of early withdrawal or dose reduction; for example, lenvatinib dosing may be adjusted to obtain an AUC value that is below the optimal cutoff $(2,430 \mathrm{ng} \bullet \mathrm{h} / \mathrm{mL})$.

Based on the findings that the optimal body weight cutoff for a similar prediction was $57.8 \mathrm{~kg}$, the predicted AUC values for weight-based dosing (daily dose of 12 or $8 \mathrm{mg}$ in patients with body weight $\geq 60 \mathrm{~kg}$ or $<60 \mathrm{~kg}$, respectively) were calculated and plotted against body weight $[36,37]$. The predicted AUC values were in the range of $1,540-2,050 \mathrm{ng} \bullet \mathrm{h} / \mathrm{mL}$ in patients with body weight $<60 \mathrm{~kg}$, and $1,410-2,310 \mathrm{ng} \cdot \mathrm{h} / \mathrm{mL}$ in those with body weight $\geq 60 \mathrm{~kg}$. These AUC ranges were similar and lower than $2,430 \mathrm{ng} \bullet \mathrm{h} / \mathrm{mL}$ in both body weight categories, indicating that the weight-based dose adjustment might efficiently reduce early withdrawal and dose reduction of lenvatinib.

Relationship between the AUC and the Efficacy of Lenvatinib in the Treatment of HCC

A major concern is that lenvatinib dose adjustment to reduce the AUC could impair efficacy. To test this, patients enrolled in the phase II trial that tested an initial daily dose of $12 \mathrm{mg}$ were divided into the low AUC group $(<2,051.1 \mathrm{ng} \bullet \mathrm{h} / \mathrm{mL})$, the intermediate AUC group $(>2,051.1$ to $\leq 2,747.1 \mathrm{ng} \bullet \mathrm{h} / \mathrm{mL})$, and the high AUC group $(>2,747.1 \mathrm{ng} \bullet \mathrm{h} / \mathrm{mL})$ to examine the relationship between AUC and efficacy. There was no trend in TTP in the three groups $[36,37]$, suggesting that a certain level of efficacy can be maintained even when the AUC is small.

Because of the lack of data on reduced-dose sorafenib, the recommended dose remains at $400 \mathrm{mg}$ twice daily even in patients with lower body weight. However, a dose of $200 \mathrm{mg}$ twice daily yields a satisfactory effect in patients with lower body weight, as in Japanese patients. The REFLECT trial showed that the $8 \mathrm{mg}$ dose used in patients weighing $60 \mathrm{~kg}$ or less was comparable or better regarding safety and efficacy than the full $12 \mathrm{mg}$ dose. These results are valuable data supporting the feasibility of determining proper dosing by weight.

\section{Quality of Life Assessment}

In the REFLECT trial, quality of life (QOL) was evaluated using two health questionnaires, the EORTC QLQ-C30 and the EORTC QLQ-HCC18 (Table 10). Baseline scores were comparable between the lenvatinib and sorafenib arms, although the scores in both arms decreased after the start of treatment [11]. 
Table 10. QOL Questionnaire

\author{
EORTC QLQ-C3O \\ Role functioning \\ Pain \\ Diarrhea \\ EORTC QLQ-HCC18 \\ Nutrition \\ Body image \\ Were you limited in doing either your work or other daily activities? \\ Were you limited in pursuing hobbies or other leisure activities? \\ Did pain interfere with your daily activities? \\ Have you had pain? \\ Have you had diarrhea? \\ Have you had problems with sense of taste? \\ Have you felt full up to quickly after beginning to eat? \\ Have you worried about getting enough nourishment? \\ Have you worried about your weight being too low? \\ Have you lost muscle from your arms or legs? \\ Have you been concerned by the appearance of your abdomen?
}

However, analysis of time to clinically meaningful deterioration showed that role functioning (nominal $p=0.0193$ ), pain (nominal $p=0.0105$ ), and diarrhea (nominal $p<0.0001$ ) in the EORTC QLQ-C30, and nutrition (nominal $p=0.0113$ ) and body image (nominal $p=$ 0.0051) deterioration in the EORTC QLQ-HCC18, occurred earlier in patients treated with sorafenib than in those treated with lenvatinib. QLQ-C30 summary scores were also better for lenvatinib than sorafenib (HR $=0.87$ ).

Maintaining good QOL in patients taking medications is critically important to improve compliance. Therefore, the detection of clinically meaningful differences between lenvatinib and sorafenib in these five critical items explains why treatment with lenvatinib could continue for longer and produce such a potent antitumor effect. These high QOL measures should be reproduced in clinical practice, and will most certainly make lenvatinib a highly tolerable and effective first-line drug for patients with HCC.

\section{Results of Exploratory Research on Blood Biomarkers}

The results of blood biomarker testing were presented at the Congress of the European Society of Medical Oncology in 2017 [38]. Blood VEGF, FGF19, and FGF23 were elevated in the lenvatinib arm but not in the sorafenib arm. Angiopoietin 2 (Ang2) was decreased in the lenvatinib arm but not in the sorafenib arm. The increase in VEGF indicates that lenvatinib is a more potent inhibitor of VEGFR1-3 activity than sorafenib. The increase in FGF19 indicates that lenvatinib is a potent inhibitor of the activity of the FGF19 receptor, FGFR4. FGF23 is secreted by osteocytes and plays a key role in phosphorus homeostasis and vitamin D metabolism [39]. Increased FGF23 is a surrogate marker of FGFR1 inhibition [40], and is part of the FGF pathway escape mechanism in response to VEGF-targeted antiangiogenic therapies [41]. Therefore, increase of FGF 23 suggests that lenvatinib is a potent inhibiter of FGFR1.

Ang2 and its receptor Tie2 are regulators of angiogenesis [42], and the role of Ang2 in adaptive tumor resistance to anti-VEGF therapy was recently identified [43], suggesting that lenvatinib is a potent agent in the adaptive tumor resistance to anti-VEGF therapy. The blood concentration of PIVKA-II was lower in the lenvatinib arm than in the sorafenib arm, which reflects the potent antitumor effect of lenvatinib.

These results provide important data to explain how the effects of lenvatinib at and above the IC50 calculated from in vitro studies, particularly its suppression of VEGF and FGF receptor activity, can be reproduced in vivo (Fig. 1). 
Kudo: Lenvatinib May Drastically Change the Treatment Landscape of Hepatocellular Carcinoma

Table 11. Objective response rate of TACE and lenvatinib (mRECIST)

\begin{tabular}{|c|c|c|c|}
\hline $\begin{array}{l}\text { Placebo arm of } \\
\text { BRISK-TA trial [49] } \\
(n=253) \\
\text { (cTACE) }\end{array}$ & $\begin{array}{l}\text { Placebo arm of } \\
\text { SPACE trial [50] } \\
(n=153) \\
\text { (DEB-TACE) }\end{array}$ & $\begin{array}{l}\text { Placebo arm of } \\
\text { TACE- } 2 \text { trial [51] } \\
(n=156) \\
\text { (DEB-TACE) }\end{array}$ & $\begin{array}{l}\text { Lenvatinib arm of } \\
\text { REFLECT trial [11] } \\
(n=478) \\
\text { (systemic) }\end{array}$ \\
\hline $42 \%$ & $28.1 \%$ & $52 \%$ & $40.6 \%$ \\
\hline
\end{tabular}

cTACE, conventional lipiodol transcatheter arterial chemoembolization. DEB-TACE, drug-eluting beads TACE.

\section{Clinical Significance of High Response Rates}

Sorafenib is a molecular targeted agent that does not yield a very high response rate, although it improves survival by maintaining stable disease for a long duration. Several drugs show significantly higher response rates than sorafenib in clinical trials; however, these trials all failed because the high response rates never led to an OS benefit (linifanib: 10.1\% per RECIST 1.1; sorafenib plus HAIC: $36.3 \%$ vs. sorafenib: $17.5 \%$ per mRECIST). In a clinical trial of second-line brivanib, the drug yielded a significantly higher ORR per mRECIST than the placebo (10 vs. $2 \%$ ), although it did not show OS benefit. The same outcomes were obtained with ramucirumab, which yielded a higher response rate per RECIST 1.1 than the placebo (7 vs. $<1 \%$ ), but could not show OS benefit. However, it would be premature to conclude from these findings that the ORR has absolutely no positive impact on survival. Measures such as disease control rate, PFS, TTP, and ORR are inherently critical factors in the antitumor effect of a drug. However, in clinical trials in HCC, other sources of "noise" overwhelm these signals, and a complex web of various factors determines whether the trial will succeed or fail. In fact, even in the RESORCE trial, which succeeded because of its excellent study design, regorafenib had a greater antitumor effect (TTP or PFS) than the placebo and a significantly greater ORR per mRECIST (11 vs. 4\%) [25]. Not only the response rate but also a clinical trial design is an important factor for the success to the OS endpoint trial of systemic therapy. However, when it comes to clinical practice, once approved a better response rate is an extremely favorable feature. Indeed, necrotic effect assessed by mRECIST in systemic therapy correlates well with OS [44-47].

A high response rate is extremely important for drugs that have moved from successful clinical trials into clinical use as mentioned above. Drugs with good response rates are not only highly effective, but also increase the motivation of physicians and patients to continue the treatment, as well as increasing compliance; in addition, they have the potential for curative conversion (e.g., surgical resection or ablation or TACE) through downstaging.

For example, TACE, the standard therapy for intermediate-stage HCC, generally has an excellent necrotic effect on tumors and is associated with a good prognosis in responders [48]. Indeed, TACE has made treatment effectiveness feasible for both physicians and patients, increasing their motivation to continue treatment. To describe TACE as the global standard for response rate, the most trustworthy source of data would be the control arms of welldesigned prospective randomized trials investigating combination therapy with TACE.

ORRs in the BRISK-TA [49], SPACE [50], and TACE-2 [51] trials were 42, 28.1, and 52\%, respectively (Table 11; Fig. 5), and the BRISK-TA results could be considered the global standard because the study had the largest enrollment and was conducted on a global scale. The ORR for TACE in the control arm of the BRISK-TA trial was $42 \%$, which was comparable to the $40.6 \%$ ORR for lenvatinib. This indicates that systemic therapy with lenvatinib can 
Kudo: Lenvatinib May Drastically Change the Treatment Landscape of Hepatocellular

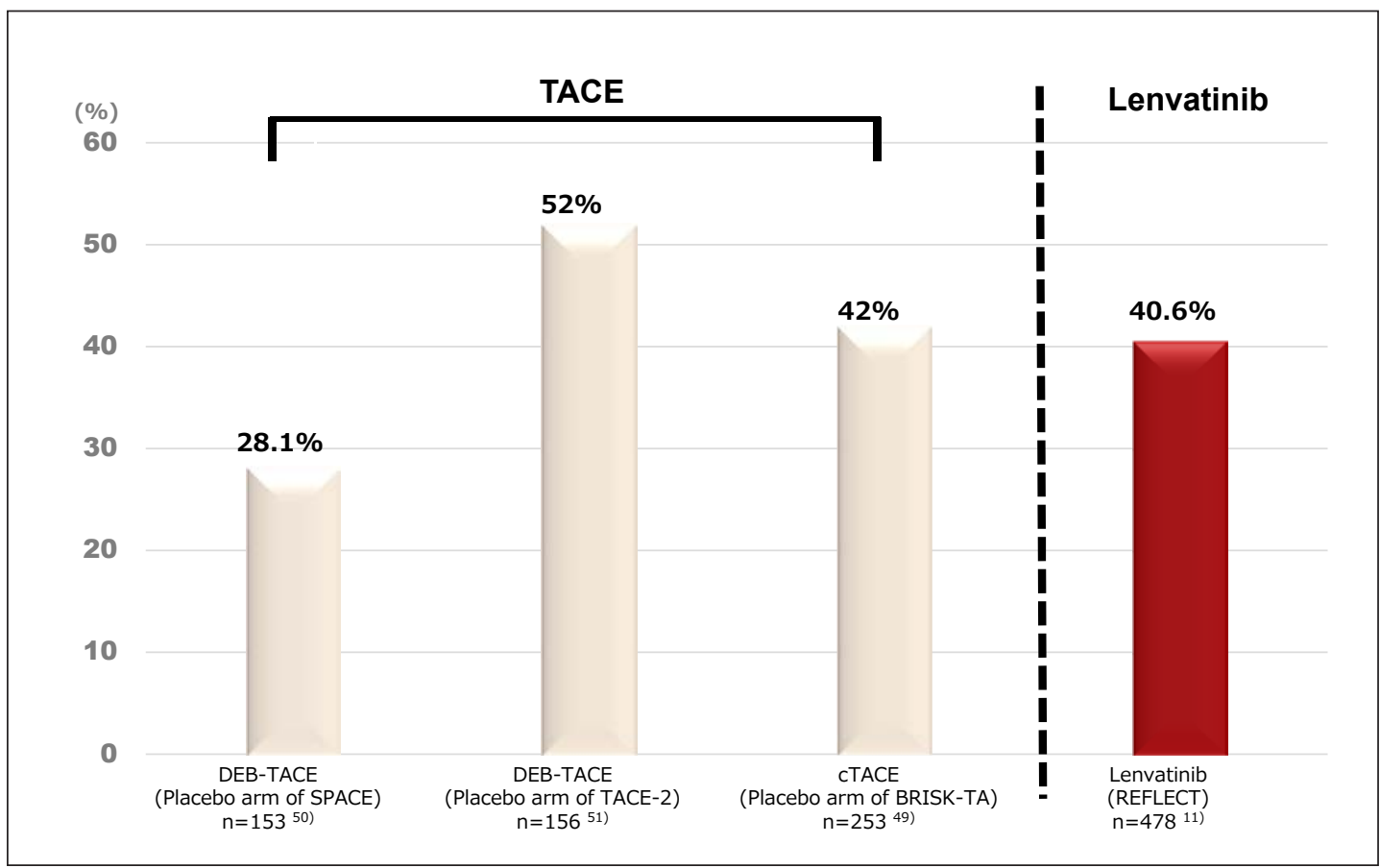

Fig. 5. Objective response rate by mRECIST TACE and lenvatinib [11, 49-51].

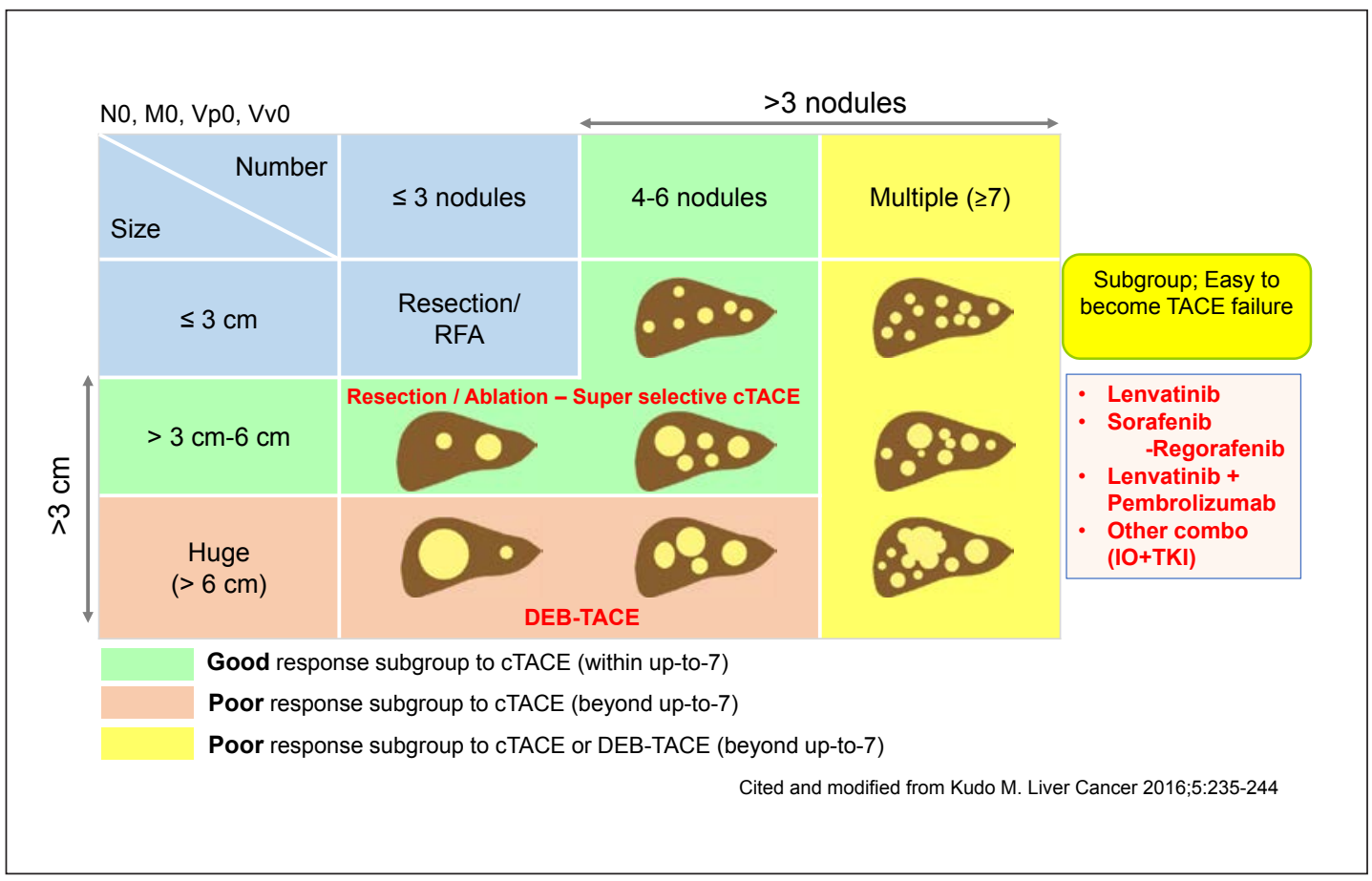

Fig. 6. Heterogeneity and treatment strategy of intermediate-stage HCC [52, 54]. 
Kudo: Lenvatinib May Drastically Change the Treatment Landscape of Hepatocellular

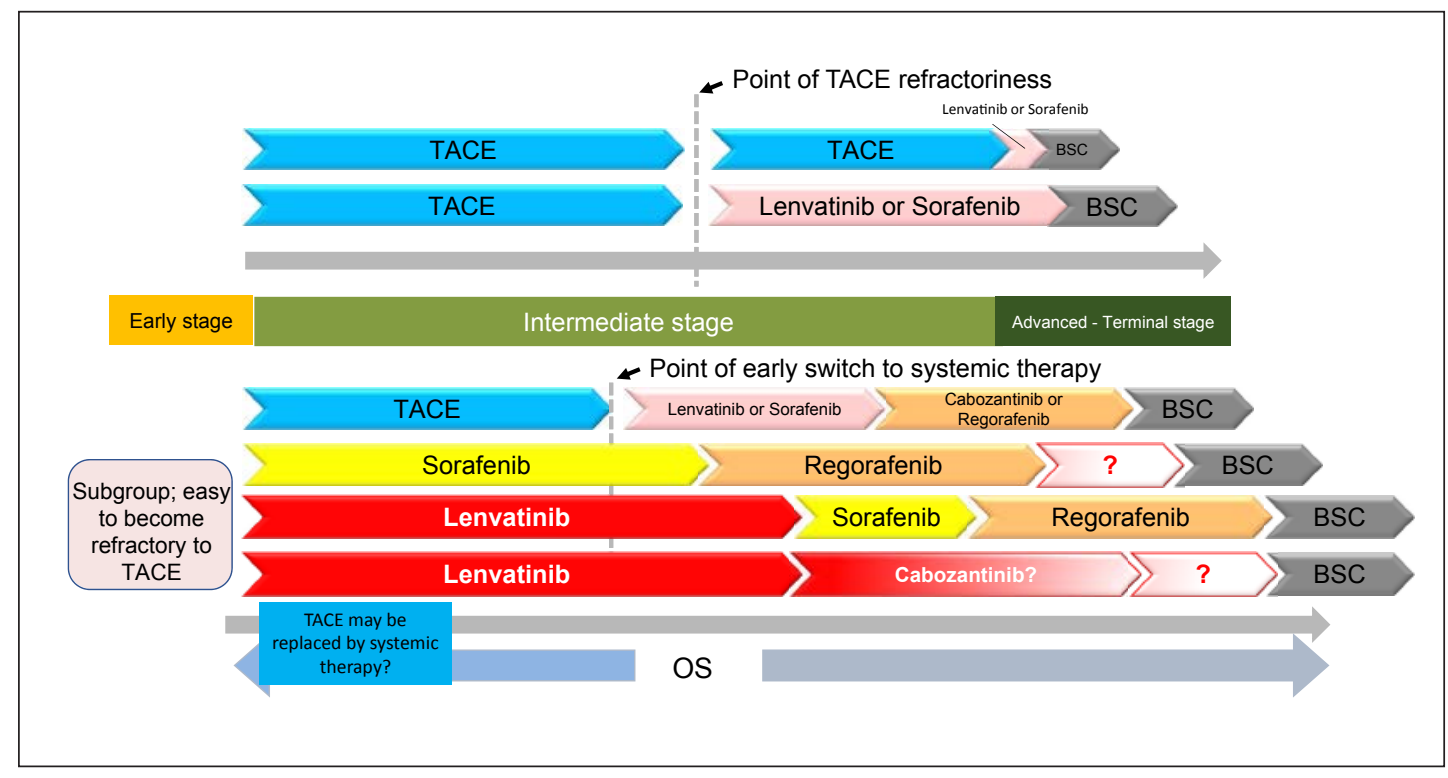

Fig. 7. Treatment strategy for systemic therapy for HCC. Identification of the subgroup that easily develops to TACE failure/refractoriness may be important.

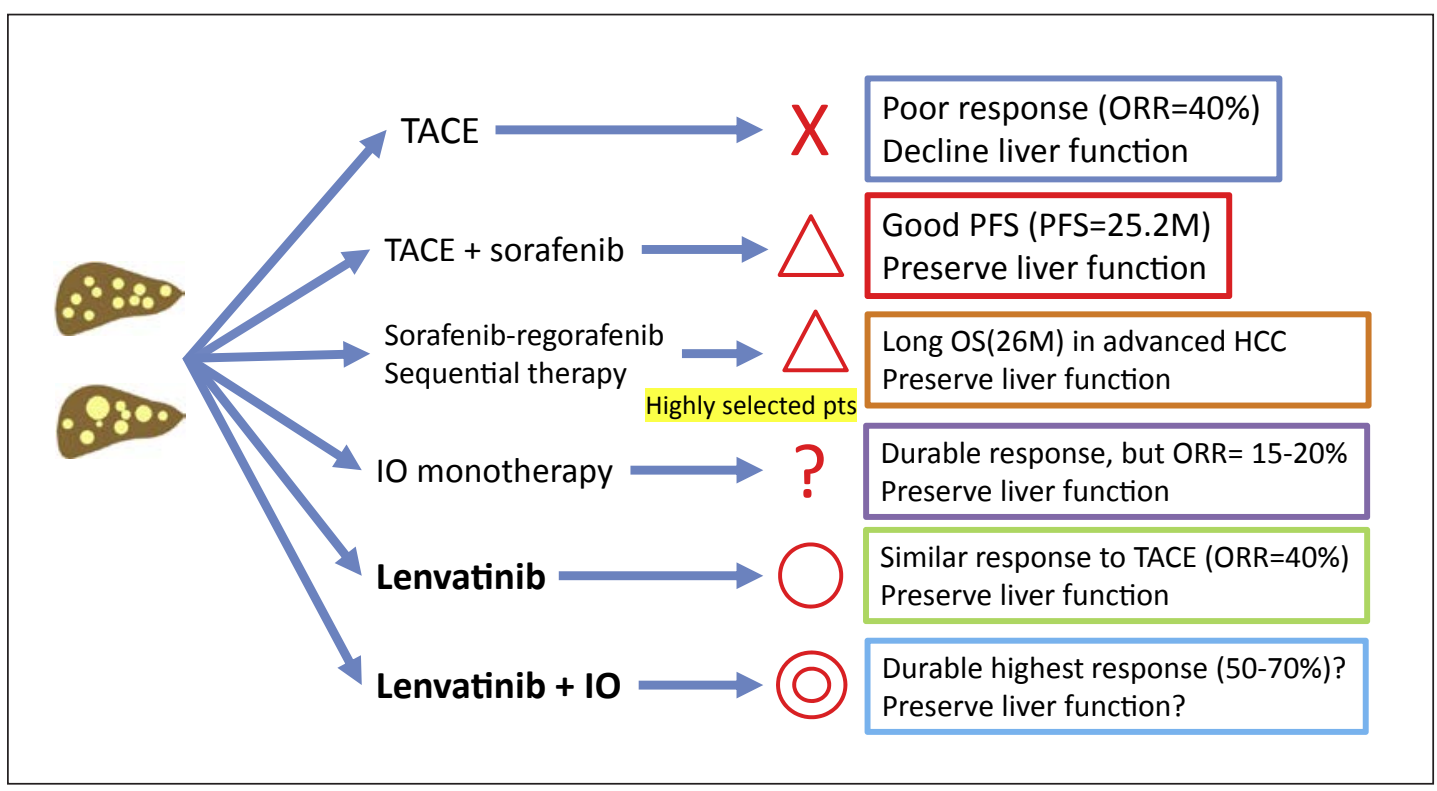

Fig. 8. Future treatment strategy of bilobar multinodular intermediate-stage HCC.

yield a comparable response to that of TACE without impairing hepatic functional reserve in patients with intermediate-stage HCC. Therefore, systemic therapy may be more effective than TACE for improving survival in a subgroup of patients with intermediate-stage HCC (Fig. 6). However, properly designed prospective clinical trials are necessary to confirm this hypothesis. The favorable properties of lenvatinib could result in a paradigm shift in the treatment of not only advanced-stage HCC, but also intermediate-stage HCC. 


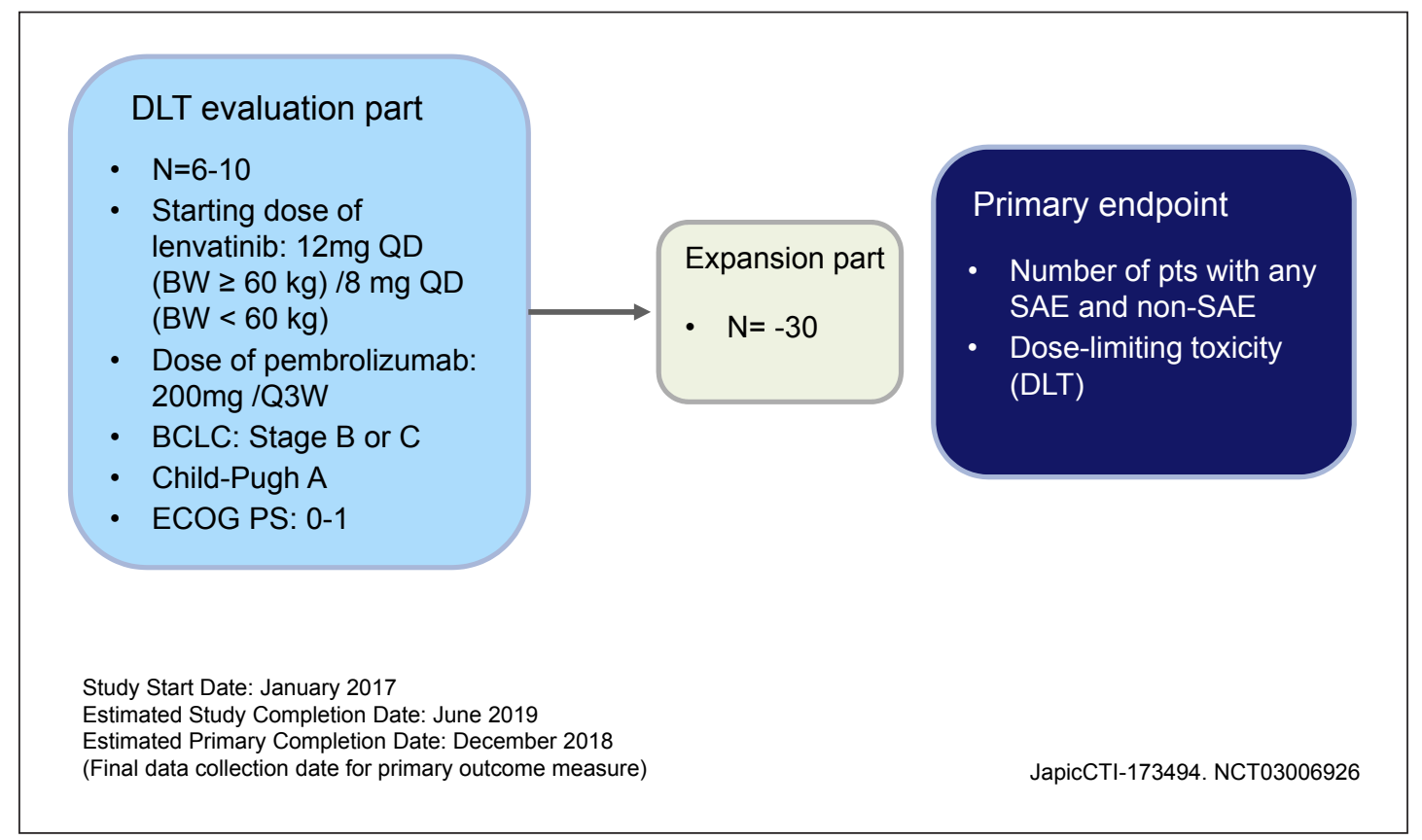

Fig. 9. Phase Ib lenvatinib plus pembrolizumab in unresectable HCC.

\section{Future Perspectives of HCC Treatment with the Introduction of Lenvatinib}

The success of the REFLECT trial will drastically change the future treatment landscape of HCC. Approval of lenvatinib would provide physicians with a first-line drug of greater potency than that of current drugs and high tolerability. Questions that remain to be answered include when to use lenvatinib rather than the other first-line drug, sorafenib, and which second-line drug should be used in patients who do not respond to lenvatinib. Regorafenib is currently the only available effective second-line agent [25,52]; however, cabozantinib will soon become available as well [53]. In this era of multimolecular targeted agents, it may be necessary to rapidly identify the subgroup of intermediate-stage HCC patients who do not respond to TACE besides advanced-stage HCC patients. TACE plus a molecular targeted agent [12] is another optional treatment to improve the clinical outcome; furthermore, systemic therapy is currently a better first choice of treatment for improving survival than TACE for certain subgroups (bilobar multinodular HCC or Kinki criteria B2 substage) of intermediatestage HCC patients who are conventionally candidates for TACE [54] (Fig. 7, 8).

\section{Conclusion}

The emergence of lenvatinib will change the treatment landscape of HCC. Most notably, the ability of lenvatinib to yield response rates as high as those of TACE indicates that systemic therapy may soon replace TACE as the standard therapy in certain subgroups of patients with intermediate-stage HCC (Fig. 6-8). Trials in other cancers show that combination therapy with immune checkpoint inhibitors such as pembrolizumab or nivolumab [55-57] yields extremely high response rates of $50-70 \%$, and it is an ideal treatment with a response that is both long-lasting and durable [58-60]. If this approach is applied as adjuvant or neoadjuvant therapy for curatively treated early-stage HCC or as an addition to or replacement for TACE 
in intermediate-stage HCC, a real cure for HCC may cease to be a dream. In fact, clinical trials of combination therapy with lenvatinib and pembrolizumab for HCC have already started (Fig. 9), leaving little doubt that the landscape of HCC treatment will undergo drastic changes in years to come.

\section{References}

1 Llovet JM, Ricci S, Mazzaferro V, Hilgard P, Gane E, Blanc JF, de Oliveira AC, et al: Sorafenib in advanced hepatocellular carcinoma. N Engl J Med 2008;359:378-390.

2 Cheng AL, Kang YK, Chen Z, Tsao CJ, Qin S, Kim JS, Luo R, et al: Efficacy and safety of sorafenib in patients in the Asia-Pacific region with advanced hepatocellular carcinoma: a phase III randomised, double-blind, placebo-controlled trial. Lancet Oncol 2009;10:25-34.

3 Kudo M: Molecular targeted agents for hepatocellular carcinoma: current status and future perspectives. Liver Cancer 2017;6:101-112.

4 Cheng AL, Kang YK, Lin DY, Park JW, Kudo M, Qin S, Chung HC, et al: Sunitinib versus sorafenib in advanced hepatocellular cancer: results of a randomized phase III trial. J Clin Oncol 2013;31:4067-4075.

5 Johnson PJ, Qin S, Park JW, Poon RT, Raoul JL, Philip PA, Hsu CH, et al: Brivanib versus sorafenib as first-line therapy in patients with unresectable, advanced hepatocellular carcinoma: results from the randomized phase III BRISK-FL study. J Clin Oncol 2013;31:3517-3524.

6 Cainap C, Qin S, Huang WT, Chung IJ, Pan H, Cheng Y, Kudo M, et al: Linifanib versus Sorafenib in patients with advanced hepatocellular carcinoma: results of a randomized phase III trial. J Clin Oncol 2015;33:172-179.

7 Zhu AX, Rosmorduc O, Evans TR, Ross PJ, Santoro A, Carrilho FJ, Bruix J, et al: SEARCH: a phase III, randomized, double-blind, placebo-controlled trial of sorafenib plus erlotinib in patients with advanced hepatocellular carcinoma. J Clin Oncol 2015;33:559-566.

8 Kudo M, Ueshima K, Yokosuka O, Ogasawara S, Obi S, Izumi N, Aikata H, et al: Randomized, open label, multicenter phase III trial comparing sorafenib plus low-dose cisplatin/fluorouracil hepatic arterial infusion chemotherapy with sorafenib alone in patients with advanced hepatocellular carcinoma: SILIUS trial. Lancet Gastroenterol Hepatol 2018, in press.

9 Vilgrain V, Pereira H, Assenat E, Guiu B, Ilonca AD, Pageaux GP, Sibert A, et al: Efficacy and safety of selective internal radiotherapy with yttrium-90 resin microspheres compared with sorafenib in locally advanced and inoperable hepatocellular carcinoma (SARAH): an open-label randomised controlled phase 3 trial. Lancet Oncol 2017;18:1624-1636.

10 Chow PK, et al: Phase III multi-centre open-label randomized controlled trial of selective internal radiation therapy (SIRT) versus sorafenib in locally advanced hepatocellular carcinoma: The SIRveNIB study. J Clin Oncol 2017;35(suppl):A4002.

11 Kudo M, Finn RS, Qin S, Han KH, Ikeda K, Piscaglia F, Baron A, et al: Lenvatinib versus sorafenib in first-line treatment of patients with unresectable hepatocellular carcinoma: a randomised phase 3 non-inferiority trial. Lancet 2018, Epub ahead of print.

12 Kudo M, Ueshima K, Torimura T, Tanabe N, Ikeda M, Aikata H, Izumi N, et al: Randomized, open label, multicenter, phase II trial comparing transcatheter arterial chemoembolization (TACE) plus sorafenib with TACE alone in patients with hepatocellular carcinoma (HCC): TACTICS trial (abstract). J Clin Oncol 2018;36(suppl 4S):206.

13 Tohyama O, Matsui J, Kodama K, Hata-Sugi N, Kimura T, Okamoto K, Minoshima Y, et al: Antitumor activity of lenvatinib (e7080): an angiogenesis inhibitor that targets multiple receptor tyrosine kinases in preclinical human thyroid cancer models. J Thyroid Res 2014;2014:638747.

14 Yamamoto Y, Matsui J, Matsushima T, Obaishi H, Miyazaki K, Nakamura K, Tohyama O, et al: Lenvatinib, an angiogenesis inhibitor targeting VEGFR/FGFR, shows broad antitumor activity in human tumor xenograft models associated with microvessel density and pericyte coverage. Vasc Cell 2014;6:18.

15 Gao L, Wang X, Tang Y, Huang S, Hu CA, Teng Y: FGF19/FGFR4 signaling contributes to the resistance of hepatocellular carcinoma to sorafenib. J Exp Clin Cancer Res 2017;36:8.

16 Sawey ET, Chanrion M, Cai C, Wu G, Zhang J, Zender L, Zhao A, et al: Identification of a therapeutic strategy targeting amplified FGF19 in liver cancer by oncogenomic screening. Cancer Cell 2011;19:347-358.

17 Miura S, Mitsuhashi N, Shimizu H, Kimura F, Yoshidome H, Otsuka M, Kato A, et al: Fibroblast growth factor 19 expression correlates with tumor progression and poorer prognosis of hepatocellular carcinoma. BMC Cancer 2012;12:56.

18 Chen Z, Xie B, Zhu Q, Xia Q, Jiang S, Cao R, Shi L, et al: FGFR4 and TGF- $\beta 1$ expression in hepatocellular carcinoma: correlation with clinicopathological features and prognosis. Int J Med Sci 2013;10:1868-1875.

19 Wang K, Lim HY, Shi S, Lee J, Deng S, Xie T, Zhu Z, et al: Genomic landscape of copy number aberrations enables the identification of oncogenic drivers in hepatocellular carcinoma. Hepatology 2013;58:706-717.

20 Ikeda M, Okusaka T, Mitsunaga S, Ueno H, Tamai T, Suzuki T, Hayato S, et al: Safety and pharmacokinetics of lenvatinib in patients with advanced hepatocellular carcinoma. Clin Cancer Res 2016;22:1385-1394. 
21 Ikeda K, Kudo M, Kawazoe S, Osaki Y, Ikeda M, Okusaka T, Tamai T, et al: Phase 2 study of lenvatinib in patients with advanced hepatocellular carcinoma. J Gastroenterol 2017;52:512-519.

22 Cheng AL, Finn RS, Qin S, Han KH, Ikeda K, Piscaglia F, Baron A, et al: Phase 3 trial of renvatinib (LEN) vs sorefenib (SOR) in first-line treatment of patients (PTS) with unresectable hepatocellular carcinoma (UHCC). ILCA Annual Conference, 2017, Abstract 0-001.

23 Kudo M, Lencioni R, Marrero JA, Venook AP, Bronowicki JP, Chen XP, Dagher L, et al: Regional differences in sorafenib-treated patients with hepatocellular carcinoma: GIDEON observational study. Liver Int 2016;36: 1196-1205.

24 Crocenzi TS, El-Khoueiry AB, Yau T, Melero I, Sangro B, Kudo M, Hsu C, et al: Nivolumab (nivo) in sorafenib (sor)-naive and -experienced pts with advanced hepatocellular carcinoma (HCC): CheckMate 040 study. J Clin Oncol 2017;35(suppl):A4013.

25 Bruix J, Qin S, Merle P, Granito A, Huang YH, Bodoky G, Pracht M, et al: Regorafenib for patients with hepatocellular carcinoma who progressed on sorafenib treatment (RESORCE): a randomised, double-blind, placebocontrolled, phase 3 trial. Lancet 2017;389:56-66.

26 Wainberg ZA, Segal NH, Jaeger D, Lee KH, Marshall J, Antonia SJ, Butler M, et al: Safety and clinical activity of durvalumab monotherapy in patients with hepatocellular carcinoma (HCC).JClin Oncol2017;35(suppl):A4071.

27 Kelley RK, Abou-Alfa GK, Bendell JC, Kim TY, Borad MJ, Yong WP, Morse M, et al: Phase I/II study of durvalumab and tremelimumab in patients with unresectable hepatocellular carcinoma (HCC): phase I safety and efficacy analyses. J Clin Oncol 2017;35(suppl):A4073.

28 Jackson R, Psarelli EE, Berhane S, Khan H, Johnson P: Impact of viral status on survival in patients receiving sorafenib for advanced hepatocellular cancer: a meta-analysis of randomized phase III trials. J Clin Oncol 2017;35:622-628.

29 Nagahama H, Okada S, Okusaka T, Ishii H, Ikeda M, Nakasuka H, Yoshimori M: Predictive factors for tumor response to systemic chemotherapy in patients with hepatocellular carcinoma. Jpn J Clin Oncol 1997;27:321324.

30 Chung GE, Lee JH, Kim HY, Hwang SY, Kim JS, Chung JW, Yoon JH, et al: Transarterial chemoembolization can be safely performed in patients with hepatocellular carcinoma invading the main portal vein and may improve the overall survival. Radiology 2011;258:627-634.

31 Kudo M: Molecular targeted therapy for hepatocellular carcinoma: where are we now? Liver Cancer 2015; 4:I-VII.

32 Kudo M: Why does every hepatocellular carcinoma clinical trial using molecular targeted agents fail? Liver Cancer 2012;1:59-60.

33 Llovet JM, Hernandez-Gea V: Hepatocellular carcinoma: reasons for phase III failure and novel perspectives on trial design. Clin Cancer Res 2014;20:2072-2079.

34 Llovet JM, Zucman-Rossi J, Pikarsky E, Sangro B, Schwartz M, Sherman M, Gores G: Hepatocellular carcinoma. Nat Rev Dis Primers 2016;2:16018.

35 Ikeda M, Kudo M, Ikeda K, Izumi N, Okusaka T, Okita K, Tamai T, et al: Subanalysis of Japanese patients in a phase 3 study of lenvatinib vs sorafenib for unresectable hepatocellular carcinoma. JSMO Annual Meeting, 2017, Abstract PS-2.

36 Tamai T, Hayato S, Hojo S, Suzuki T, Okusaka T, Ikeda K, Kumada H: Dose finding of lenvatinib in subjects with advanced hepatocellular carcinoma based on population pharmacokinetic and exposure-response analyses. J Clin Pharmacol 2017;57:1138-1147.

37 Kudo M: Lenvatinib in advanced hepatocellular carcinoma. Liver Cancer 2017;6:253-263.

38 Finn RS, Kudo M, Cheng AL, Wyrwicz L, Ngan R, Blanc JF, Baron AD, et al: Analysis of serum biomarkers (BM) in patients (pts) from a phase 3 study of lenvatinib (LEN) vs sorafenib (SOR) as first-line treatment for unresectable hepatocellular carcinoma (uHCC). Ann Oncol 2017;28(suppl 5):LBA30.

39 Wohrle S, Henninger C, Bonny O, Thuery A, Beluch N, Hynes NE, Guagnano V, et al: Pharmacological inhibition of fibroblast growth factor (FGF) receptor signaling ameliorates FGF23-mediated hypophosphatemic rickets. J Bone Miner Res 2013;28:899-911.

40 Kim KB, Chesney J, Robinson D, Gardner H, Shi MM, Kirkwood JM: Phase I/II and pharmacodynamic study of dovitinib (TKI258), an inhibitor of fibroblast growth factor receptors and VEGF receptors, in patients with advanced melanoma. Clin Cancer Res 2011;17:7451-7461.

41 Bergers G, Hanahan D: Modes of resistance to anti-angiogenic therapy. Nat Rev Cancer 2008;8:592-603.

42 Gerald D, Chintharlapalli S, Augustin HG, Benjamin LE: Angiopoietin-2: an attractive target for improved antiangiogenic tumor therapy. Cancer Res 2013;73:1649-1657.

43 Rigamonti N, Kadioglu E, Keklikoglou I, Wyser Rmili C, Leow CC, De Palma M: Role of angiopoietin-2 in adaptive tumor resistance to VEGF signaling blockade. Cell Rep 2014;8:696-706.

44 Lencioni R, Montal R, Torres F, Park JW, Decaens T, Raoul JL, Kudo M, et al: Objective response by mRECIST as a predictor and potential surrogate end-point of overall survival in advanced HCC. J Hepatol 2017;66:11661172.

45 Arizumi T, Ueshima K, Takeda H, Osaki Y, Takita M, Inoue T, Kitai S, et al: Comparison of systems for assessment of post-therapeutic response to sorafenib for hepatocellular carcinoma. J Gastroenterol 2014;49:1578-1587.

46 Meyer T, Palmer DH, Cheng AL, Hocke J, Loembe AB, Yen CJ: mRECIST to predict survival in advanced hepatocellular carcinoma: Analysis of two randomised phase II trials comparing nintedanib vs sorafenib. Liver Int 2017;37:1047-1055. 
Kudo: Lenvatinib May Drastically Change the Treatment Landscape of Hepatocellular Carcinoma

47 Takada J, Hidaka H, Nakazawa T, Kondo M, Numata K, Tanaka K, Matsunaga K, et al: Modified response evaluation criteria in solid tumors is superior to response evaluation criteria in solid tumors for assessment of responses to sorafenib in patients with advanced hepatocellular carcinoma. BMC Res Notes 2015;8:609.

48 Llovet JM, Real MI, Montana X, Planas R, Coll S, Aponte J, Ayuso C, et al: Arterial embolisation or chemoembolisation versus symptomatic treatment in patients with unresectable hepatocellular carcinoma: a randomised controlled trial. Lancet 2002;359:1734-1739.

49 Kudo M, Han G, Finn RS, Poon RT, Blanc JF, Yan L, Yang J, et al: Brivanib as adjuvant therapy to transarterial chemoembolization in patients with hepatocellular carcinoma: a randomized phase III trial. Hepatology 2014; 60:1697-1707.

50 Lencioni R, Llovet JM, Han G, Tak WY, Yang J, Guglielmi A, Paik SW, et al: Sorafenib or placebo plus TACE with doxorubicin-eluting beads for intermediate stage HCC: the SPACE trial. J Hepatol 2016;64:1090-1098.

51 Meyer T, Fox R, Ma YT, Ross PJ, James MW, Sturgess R, Stubbs C, et al: Sorafenib in combination with transarterial chemoembolisation in patients with unresectable hepatocellular carcinoma (TACE 2): a randomised placebo-controlled, double-blind, phase 3 trial. Lancet Gastroenterol Hepatol 2017;2:565-575.

52 Kudo M: Regorafenib as second-line systemic therapy may change the treatment strategy and management paradigm for hepatocellular carcinoma. Liver Cancer 2016;5:235-244.

53 Abou-Alfa GK, Meyer T, Cheng AL, Anthony B, Khoueiry EI, Rimassa L, et al: Cabozantinib (C) versus placebo (P) in patients (pts) with advanced hepatocellular carcinoma (HCC) who have received prior sorafenib: results from the randomized phase III CELESTIAL trial. J Clin Oncol 2018;36(suppl 4S):A207.

54 Kudo M, Arizumi T, Ueshima K, Sakurai T, Kitano M, Nishida N: Subclassification of BCLC B stage hepatocellular carcinoma and treatment strategies: proposal of modified Bolondi's subclassification (Kinki criteria). Dig Dis 2015;33:751-758.

55 Finn RS, Chan SL, Zhu AX, Knox JJ, Cheng AL, Siegel AB, et al: KEYNOTE-240: randomized phase III study of pembrolizumab versus best supportive care for second-line advanced hepatocellular carcinoma (abstract). J Clin Oncol 2017;35(suppl 4S):TPS503.

56 Sangro B, Park JW, Dela Cruz C, Anderson J, Lang L, Neely J, Shaw JW, et al: A randomized, multicenter, phase 3 study of nivolumab vs sorafenib as first-line treatment in patients (pts) with advanced hepatocellular carcinoma (HCC): CheckMate-459 (abstract). J Clin Oncol 2016;34(suppl):TPS4147.

57 El-Khoueiry AB, Sangro B, Yau T, Crocenzi TS, Kudo M, Hsu C, Kim TY, et al: Nivolumab in patients with advanced hepatocellular carcinoma (CheckMate 040): an open-label, non-comparative, phase 1/2 dose escalation and expansion trial. Lancet 2017;389:2492-2502.

58 Taylor M, Dutcus C, Schmidt E, Bagulho T, Li D, Shumaker R, Rasco D: A phase 1b trial of lenvatinib (LEN) plus pembrolizumab (PEM) in patients with selected solid tumors. Ann Oncol 2016;27(suppl 6):776PD.

59 Makker V, Rasco DW, Dutcus CE: A phase Ib/II trial of lenvatinib (LEN) plus pembrolizumab (Pembro) in patients (Pts) with endometrial carcinoma. J Clin Oncol 2017;35(suppl):A5598.

60 Lee C-H, Makker V, Rasco D, Taylor M, Dutcus C, Shumaker R, Schmidt EV, et al: A phase 1b/2 trial of lenvatinib plus pembrolizumab in patients with renal cell carcinoma. Ann Oncol 2017;28(suppl 5):8470. 